\title{
Influence of Temperature and Humidity on the Physiological Indices of Stress in the Obudu Mountain Landscape Environment, Nigeria
}

\author{
Henry Ojobo ${ }^{1}$, Bukar Usman Wakawa² \& Aminu Umar ${ }^{2}$ \\ ${ }^{1}$ Department of Architecture, Faculty of Environmental Sciences, Kaduna State University, Nigeria \\ ${ }^{2}$ Department of Architecture, School of Environmental Technology, Abubakar Tafawa Balewa University, Nigeria \\ Correspondence: Henry Ojobo, Department of Architecture, Faculty of Environmental Sciences, Kaduna State \\ University, Nigeria. Email: ojheny@gmail.com
}

Received: January 20, 2016

Accepted: January 31, 2016

Online Published: January 9, 2017

doi:10.5539/enrr.v7n1p11

URL: http://dx.doi.org/10.5539/enrr.v7n1p11

\begin{abstract}
Stress can be viewed in terms of the contribution of urbanization, lifestyle changes and the ameliorating potential of nature related environments. This study explored the influence of temperature and humidity of the mountain landscape environment on the physiological indices of individuals. 38 respondents formed a single within-group study sample. Measures of Physiological indices including blood pressure, pulse rate and respiratory rate as well as ambient environment conditions were carried out both at the urban and mountain landscape environments. Findings imply that temperature and humidity are aspects of the mountain landscape environment conditions that combine to influence human physiological wellbeing. Therefore, Individuals confronted with many sources of stress from daily engagements in urban environments can obtain short term relief in the mountain landscape environment.
\end{abstract}

Keywords: temperature, humidity, physiological indices, stress, mountain landscape, Obudu

\section{Introduction}

In healthcare management, stress is vital in considering the etiology of a diverse range of common health challenges, including cardiovascular diseases, anxiety disorders, obesity and depression (Lee and Oh, 2010; Probst, 2013). In landscape studies, stress is viewed in terms of the contribution of urbanization, lifestyle changes and the ameliorating potential of nature-related environments (Hartig et al., 2014). Researchers have variously tried to conceptualize the negative attributes of stress (e.g. forgetfulness, distractions, mistakes and illness) and also critically assess the positive aspects of restoration linked to nature (e.g. feeling relaxed, effectiveness, productivity and wellbeing) (Bergdahl and Bergdahl, 2002; Kaplan, 2001; Kaplan and Kaplan, 2011; Tsunetsugu et al., 2013). The assessment of the physiological stress response requires a stressor that is critical enough to produce a palpable response and also sufficient to show variations between individuals (Kajantie and Phillips, 2006). The physiological responses that are the outcome of stressful experiences (Campbell and Ehlert, 2012) manifest in a variety of ways (Hughes et al., 2014). They include changes in respiration, pulse rate, blood pressure, electro-dermal activity and salivary cortisol (Nater et al., 2005; Pan et al., 1993).

Consequently, several researchers have suggested an association between ambient environmental conditions and physiological responses (Chen et al., 2013; Hozawa et al., 2011; Modesti et al., 2006; Murakami et al., 2011). For example, Kampmann and Bröde (2009) suggested that the combined effect of temperature and humidity generally influences stress. Abdulla and Taka (1988) claimed that seasonal climatic variations in temperature and humidity have a small overall effect on blood pressure. Also, Chifamba et al. (1998) asserted that low temperatures heighten sympathetic nervous system activity and increase catecholamine secretion, which in turn influence heart rate and blood pressure increases. However, quite a number of studies pertaining to variations in physiological responses of individuals have been carried out in natural environments, especially forests, compared with urban areas (Horiuchi et al., 2014; Park et al., 2007; Tsunetsugu, et al., 2013; van den Berg et al., 2010).

Particularly, Yamaguchi et al. (2006) measured salivary amylase activity before and after walking in urban and forest environments. It was found that salivary amylase activity was a good indicator of variations in sympathetic nervous activity. In addition, findings from the study revealed that people experience less stress during contact with forest environments. Another study that provided evidence that contact with natural environments, 
especially forests, evokes physiological responses is that of Lee et al. (2009). In their study, they compared the responses of participants who visited both forest and urban environments. It was revealed that variations in responses in terms of salivary cortisol concentration, diastolic blood pressure and pulse rate in a forest landscape environment indicate stress mitigation, enhancement of autonomic nervous system relaxation and increased positive emotion. On the whole, natural environments stimulate physiological responses which could be partly due to psychological reactions and the restorative attributes inherent in nature (Brown et al., 2013). On the other hand, urban environments stimulate physiological responses as a result of their stress-inducing attributes (Lin and Lai, 1995; Ulrich et al., 1991; Yang et al., 2012). Whereas studies concerning the influence of environmental conditions on wellbeing have utilized forests as study contexts, no study was found to have used mountains. Mountains are high altitude environments: therefore, ambient conditions such as temperature and humidity are expected to be significantly different from those in urban environments.

This study examined variations in blood pressure, pulse rate and respiratory rate of individuals between contact with the urban and mountain landscape environments. It set out to establish whether there is sufficient evidence to conclude that there is an adequate difference between the ambient conditions of the urban and mountain environment to influence variations in physiological responses. This is in keeping with the assertion of Berto (2014) that environmental conditions are precursory factors related to stress mechanisms which mediate the relationship between the environment and human wellbeing. It also illuminates the relationship between ambient environment conditions, physiological responses and stress mitigation. According to Cairns Jr et al. (1993), changes in human physiological responses are highly sensitive early alerts indicating stress. Therefore, this study explores the influence of ambient conditions of the mountain landscape environment, specifically temperature and humidity, on the physiological indices of individuals in a manner that would mitigate stress and enhance wellbeing. To achieve this objective, the study specifically tests the following hypotheses:

1) Ambient mountain landscape environment conditions have significant influence on systolic blood pressure.

2) Ambient mountain landscape environment conditions have significant influence on diastolic blood pressure.

3) Ambient mountain landscape environment conditions have significant influence on pulse rate.

4) Ambient mountain landscape environment conditions have significant influence on respiratory rate.

\section{Methodology}

\subsection{Study Population}

The main units of assessment in this study were urban dwellers. A non-probability convenience sampling method was deployed in determining the sample. Because of the experimental nature of the study and following the idea of Creswell (2012), the sample was made up of only individuals who volunteered and agreed to be studied. A few of the volunteers who were known acquaintances at the Benue state university, Nigeria were initially co-opted by one of the authors. These initial volunteers then co-opted others to make up the sample. Also, individuals' behaviour was a determinant in the selection of volunteers who eventually constituted the sample (Weathington et al., 2010). Only individuals who were non-smokers (Lee et al., 2013), not on any form of cardiovascular related drug and not at the time of study suffering from any acute illnesses were selected (Abdulla and Taka, 1988). This process was conducted through verbal questioning (Okada and Kakehashi, 2014). Forty respondents, comprising lecturers and students between the ages of 20 and 40 years, were recruited from the urban environment of Makurdi, Benue State, Nigeria. A day before the commencement of the experiment, two of the respondents opted out: one was unable to participate due to time factors and the other admitted not being psychologically stable for the experiments. Thirty-eight respondents, including 16 males and 22 females, gave informed written consent to participate in the study at no fee. All the thirty-eight respondents formed a single within-group experimental study sample.

\subsection{Study Locations}

This study involved comparison between an urban and a mountain landscape environment. Makurdi, the urban environment, is the capital city of Benue State, Nigeria. It was used as the pre-test environment. It has a tropical savanna climate and lies on an altitude of about $104 \mathrm{~m}$ above sea level. The intervention environment was the Obudu mountains in Obanliku local government area of Cross River State, Nigeria. It has a semi-temperate mountain climate and an altitude of between $1700 \mathrm{~m}$ and $1765 \mathrm{~m}$ above sea level. It is characterized by diverse landscape attributes such as waterfalls, grottos, river, forest reserve, a $70 \mathrm{~m}$ long canopy walkway, bird watching platforms and a cable car ride. The cable car ride affords a moving view of prominent undulating mountain 
formations covered by near dense but fascinating green vegetation. Hence, the environment offers serene ambience suitable for stress mitigation.

\subsection{Materials and Procedure}

The physiological indices data were collected through observations. The observations involved physical measurements and recording of the respondents' physiological indices and ambient environment conditions. The experimentation was carried out between $28^{\text {th }}$ January and $3^{\text {rd }}$ February 2014. The experimental protocol spanned seven days, as shown in Figure 1. Pre-test measures were carried out at the urban environment on $28^{\text {th }}, 29^{\text {th }}$ and $30^{\text {th }}$ January, which represented the first three days of the study. Intervention measures were carried out in the mountain landscape environment during the following three days, $1^{\text {st }}, 2^{\text {nd }}$ and $3^{\text {rd }}$ February. Three qualified medics assisted in carrying out measurements in the urban environment while two assisted in the mountain landscape environment. The respondents were verbally briefed at the beginning of the study on the measures to be taken, which included systolic blood pressure, diastolic blood pressure, pulse rate and respiratory rate measurements. This briefing was done in order to alleviate any fear and anxiety that the respondents might be feeling concerning the procedure (O'Brien et al., 2003).

The pre-test centre for the measurements was set at the Benue State University Makurdi medical school private dining hall, which was within a $10 \mathrm{~km}$ radius and about fifteen minutes' drive from the location of each respondent. Daily activities engaged in by respondents in the pre-test environment included walking from one lecture venue to another as well as receiving lectures in non-air conditioned crowded halls. Measurements were carried out between $6 \mathrm{pm}$ and $8 \mathrm{pm}$ during the three-day period in the urban environment. Each respondent was allowed to rest in a seated position on arrival at the pre-test centre for at least five minutes before their blood pressure, pulse rate and respiratory rate were taken. Respondents were asked to switch off their phones to avoid distraction and disturbance. Systolic blood pressure (BP), diastolic blood pressure (BP), pulse rate and respiratory rate of each respondent were recorded for the three consecutive days.

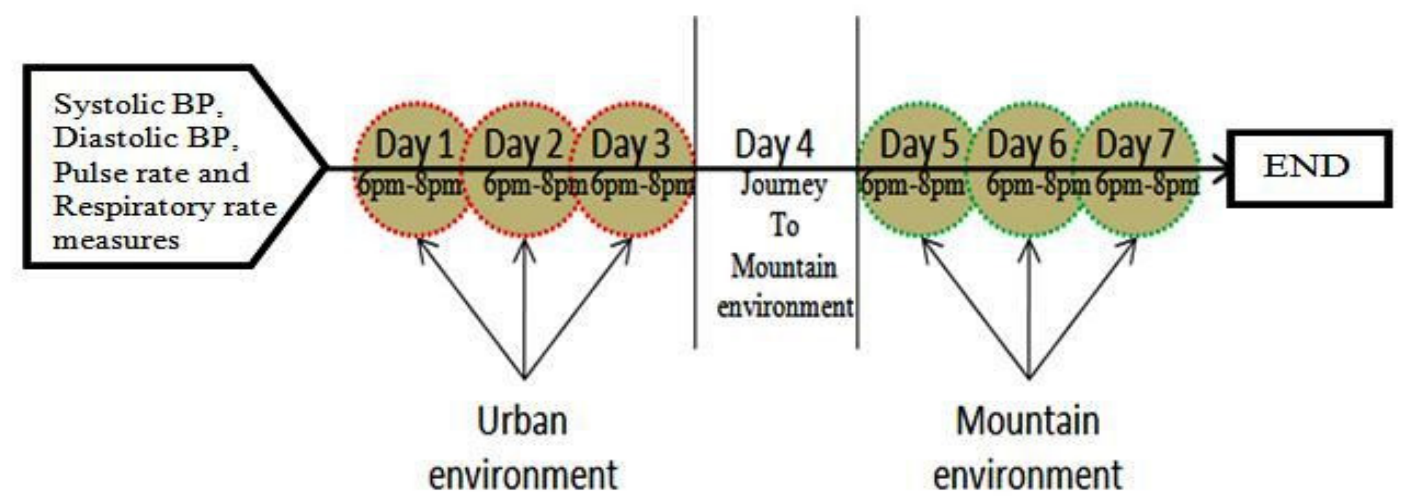

Figure 1. The seven-day experimental procedure showing measurement time

Respondents were transported by road on a journey that lasted four hours to the Obudu mountain landscape environment on the $31^{\text {st }}$ of January 2014. They were allowed to rest and interact freely on arrival but measurements were not taken that day in order to check the effect of 'travel fatigue' (Waterhouse et al., 2004). The activities individuals engaged in during the three days post-test intervention study at the Obudu mountain landscape environment were both active and passive. The active activities included forest walks and swimming in the river while the passive activities involved meditative moments in the forest, mountain vantage point and river areas. Systolic BP, diastolic BP, pulse rate and respiratory rates were carried out every day throughout the three-day stay in the mountain landscape environment using the same equipment and process as obtained in the urban environment. Similar to the procedure in the urban environment, measures were carried out between $6 \mathrm{pm}$ and $8 \mathrm{pm}$ each day. The intervention measures were also carried out within the same time frame (6pm to $8 \mathrm{pm})$ in order to check the influence of circadian effects (Biaggioni, 2008; Ochiai et al., 2015). Blood pressure measurement was performed by the medics using the standard mercury sphygmomanometer and the auscultatory technique. The pulse rate and respiratory rate measurements immediately followed the blood pressure measurement in a consecutive pattern. 
To provide real-time measurement of temperature and humidity, an Onset Hobo U12 model data logger was used. Its real-time collection and presentation of data with sensors that are able to respond to parameters beyond the normal range makes the data logger an invaluable instrument for experimental data collection and analysis (Waghmare and Chatur, 2012). The temperature and humidity data extraction took place at the same time of day as the physiological indices of respondents were being measured in both the urban and mountain landscape environments. The device was set up and launched in the urban environment a day before the commencement of measures of physiological indices. This was to ensure that the correct range of data was recorded. It recorded series of real-time temperature and humidity data. On the day of the journey to the mountain landscape environment, the device was removed from its position and recording stopped. On arrival at the mountain landscape environment on the $31^{\text {st }}$ of January 2014, the device was re-launched. It was fixed outdoors following the same method employed in the urban environment. The device recording was stopped on conclusion of physiological measures at the mountain landscape environment.

This set of data captured the three-day experimental period in the urban environment and similarly at the mountain environment, with one-hour intervals between measurements (Jamaludin et al., 2013). The temperature and humidity data were eventually downloaded from the device into a personal computer for data analysis. Data which did not fall within the experimental days were excluded.

\section{Data Analysis}

The data collected were analysed using the Statistical Package for the Social Sciences (SPSS version 19) software. T-tests were used to ascertain the differences in temperature and humidity between the urban and mountain landscape environments. Multiple linear regression analysis was employed to determine the contribution and association of temperature and humidity to changes in systolic and diastolic BP, pulse rate and respiratory rate.

\section{Results}

The values acquired from temperature and humidity data were analysed and the results of the t-test obtained are shown in Table 1. From the table, highly significant difference exist in temperature $(t=21.31, P<0.05)$ and humidity $(\mathrm{t}=-11.815, \mathrm{P}<0.05)$ between the urban and the mountain environment. The mean values of temperature (urban: $30.55^{\circ} \mathrm{C} \pm 4.22$, mountain: $21.86^{\circ} \mathrm{C} \pm 2.26$ ) and humidity (urban: $45 \% \pm 20.10$, mountain: $75 \%$ \pm 10.47 ) indicate reduced temperature and increased humidity in the mountain environment. The mean difference in temperature is $8.7^{\circ} \mathrm{C}$, while the mean difference in humidity is $30 \%$.

Table 1. Difference in ambient conditions between the urban and mountain environment

\begin{tabular}{cccccc}
\hline Ambient condition & Environment & Mean & Std. Deviation & $\mathrm{t}$ & Sig. (2-tailed) \\
\hline \multirow{2}{*}{ Temperature } & Urban & 30.5536 & 4.22536 & \multirow{2}{*}{21.313} & .000 \\
& Mountain & 21.8662 & 2.26017 & & \\
\multirow{2}{*}{ Humidity } & Urban & 44.9367 & 20.10641 & \multirow{2}{*}{-11.815} & .000 \\
& Mountain & 75.0163 & 10.47910 & & \\
\hline
\end{tabular}

To ascertain the contribution and association of temperature and humidity to the mean change in systolic and diastolic BP, multiple linear regression analysis was employed. Table 2 shows a competing regression model between the urban and the mountain environment relative to the association of temperature and humidity on systolic BP. Based on the coefficients of determination (urban: $\mathrm{R}^{2} 0.28, \mathrm{~F}=8.60, \mathrm{P}<0.05$; mountain: $\mathrm{R}^{2} 0.47, \mathrm{~F}$ $=7.20, \mathrm{P}<0.05$ ), it could be concluded that the model is a good one, given that other latent factors may exist which were not included in the regression model. However, the model indicates that the independent variables account for about $28 \%$ and $47 \%$ of the variance in systolic BP in the urban and mountain landscape environments, respectively. The model also shows that temperature and humidity are significantly related to systolic BP $(\mathrm{P}<0.05)$ in both the urban and the mountain landscape environment.

Having shown the overall amount of variance in the dependent variable on account of the independent variables, the contribution of temperature and humidity in predicting systolic BP is examined. Temperature (urban: $\beta=$ -0.69 ; mountain: $\beta=-0.72$ ) and humidity (urban: $\beta=-0.68$; mountain: $\beta=-0.88$ ) are inversely related to systolic $\mathrm{BP}$ in the urban and mountain environments. This suggests that a unit increase in temperature and humidity in both environments would lead to a decrease in systolic BP. This signifies that when humidity is held constant in the model, a unit increase in temperature accounts for about a $0.69 \mathrm{mmHg}$ and $0.72 \mathrm{mmHg}$ decrease in systolic 
BP in the urban and mountain landscape environments respectively. On the other hand, when temperature is held constant, a unit increase in humidity accounts for a $0.68 \mathrm{mmHg}$ and $0.88 \mathrm{mmHg}$ decrease in systolic BP in the urban and mountain landscape environment respectively.

Table 2. Multiple regression analysis of temperature and humidity on systolic blood pressure

\begin{tabular}{|c|c|c|c|c|c|}
\hline & & Unstandardized Coefficients & \multirow{2}{*}{$\begin{array}{l}\text { Standardized Coefficients } \\
\text { Beta }\end{array}$} & \multirow[t]{2}{*}{$\mathrm{t}$} & \multirow[t]{2}{*}{ Sig. } \\
\hline & $\mathrm{B}$ & Std. Error & & & \\
\hline (Constant) & 208.471 & 21.680 & & 9.616 & $.000 * *$ \\
\hline Temperature & -2.197 & .576 & -.694 & -3.813 & $.001 * *$ \\
\hline Humidity & -.453 & .121 & -.681 & -3.739 & $.001 * *$ \\
\hline$F=8.605, P<0.05$ & $\mathrm{R}=.569^{\mathrm{b}}, \mathrm{R}^{2}=.286$ & & & & \\
\hline \multirow{2}{*}{$\begin{array}{l}\text { Model } \\
\text { (mountain environment) }\end{array}$} & \multicolumn{2}{|c|}{ Unstandardized Coefficients } & Standardized Coefficients & $\mathrm{t}$ & Sig. \\
\hline & $\mathrm{B}$ & Std. Error & Beta & & \\
\hline (Constant) & 427.230 & 55.087 & & 7.756 & $.000 * *$ \\
\hline Temperature & -7.936 & 1.525 & -0.722 & -5.203 & $.000 * *$ \\
\hline Humidity & -1.708 & .326 & -0.881 & -5.232 & $.000 * *$ \\
\hline
\end{tabular}

$\mathrm{F}=7.209, \mathrm{P}<0.05, \quad \mathrm{R}=.683^{\mathrm{b}}, \mathrm{R}^{2}=.466$

a. Dependent Variable: Systolic blood pressure ** Significant at $0.05 \%$ (Significant),

b. Independent Variables: Temperature, Humidity

Turning now to the regression model of temperature and humidity on diastolic BP, Table 3 reveals a good model based on the values of the coefficients of determination (urban: $\mathrm{R}^{2} 0.52, \mathrm{~F}=19.40, \mathrm{P}<0.05$; mountain: $\mathrm{R}^{2} 0.48$, $\mathrm{F}=16.43, \mathrm{P}<0.05)$, excluding other factors not considered in the model. This model suggests that temperature and humidity account for about $52 \%$ and $48 \%$ of the variance in diastolic BP in the urban and mountain environments, respectively. In addition, the model indicates that temperature and humidity are significantly related to diastolic BP $(\mathrm{P}<0.05)$ in both the urban and the mountain landscape environment. The contribution of temperature and humidity in predicting diastolic BP is also examined in this case. Similarly, the result shows that temperature (urban: $\beta=-0.89$; mountain: $\beta=-0.87$ ) and humidity (urban: $\beta=-0.85$; mountain: $\beta=-0.82$ ) are also inversely associated with diastolic BP in the urban and the mountain landscape environment. This shows that a unit increase in each of the independent variables (temperature, humidity) in the model would lead to a decrease in diastolic BP in both environments. As revealed by the standardized beta coefficient $(\beta)$, when humidity is held constant, a unit increase in temperature accounts for a decrease of more than $0.80 \mathrm{mmHg}$ in diastolic BP in both the urban and the mountain landscape environment, and vice versa.

Table 3. Multiple regression analysis of temperature and humidity on diastolic blood pressure

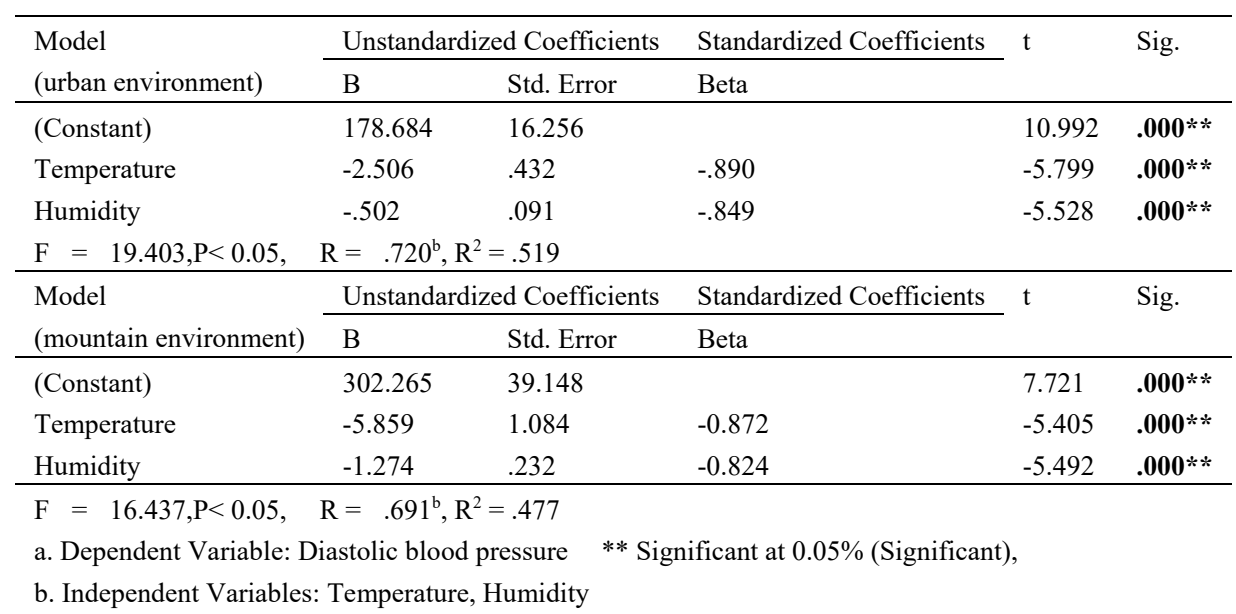

The results in Table 4 reveal a model similar to the one in Tables 2 and 3 . In this case, the coefficients of determination (urban: $\mathrm{R}^{2} 0.34, \mathrm{~F}=9.28, \mathrm{P}<0.05$; mountain: $\mathrm{R}^{2} 0.30, \mathrm{~F}=7.92, \mathrm{P}<0.05$ ) also indicate that the model is reliable, barring other factors that are not included. This means that temperature and humidity explain 
about $34 \%$ and $30 \%$ of the variation in pulse rate in both the urban and mountain environments. It is apparent from the results that the predictive strengths of temperature (urban: $\beta=-0.67$; mountain: $\beta=-0.93$ ) and humidity (urban: $\beta=-0.74$; mountain: $\beta=-0.71$ ) are inversely related to pulse rate. Holding humidity constant in the model, a unit increase in temperature accounts for a variation in pulse rate of more than $0.67 \mathrm{beats} / \mathrm{min}$ in the urban environment and more than 0.93 beats/min in the mountain landscape environment. On the other hand, humidity accounts for a difference in pulse rate of more than 0.70 beats $/ \mathrm{min}$ in both environments when temperature is held constant.

Table 4. Multiple regression analysis of the effect of temperature and humidity on pulse rate

\begin{tabular}{|c|c|c|c|c|c|}
\hline \multirow{2}{*}{$\begin{array}{l}\text { Model } \\
\text { (urban environment) }\end{array}$} & \multicolumn{2}{|c|}{ Unstandardized Coefficients } & Standardized Coefficients & \multirow[t]{2}{*}{$\mathrm{t}$} & \multirow[t]{2}{*}{ Sig. } \\
\hline & $\mathrm{B}$ & Std. Error & Beta & & \\
\hline (Constant) & 117.163 & 9.624 & & 12.174 & $.000 * *$ \\
\hline Temperature & -.949 & .256 & -.666 & -3.708 & $.001 * *$ \\
\hline Humidity & -.220 & .054 & -.736 & -4.094 & $.000 * *$ \\
\hline \multicolumn{6}{|c|}{$\mathrm{F}=9.288, \mathrm{P}<0.05, \quad \mathrm{R}=.583^{\mathrm{b}}, \mathrm{R}^{2}=.340$} \\
\hline \multirow{2}{*}{$\begin{array}{l}\text { Model } \\
\text { (mountain environment) }\end{array}$} & \multicolumn{2}{|c|}{ Unstandardized Coefficients } & Standardized Coefficients & \multirow[t]{2}{*}{$\mathrm{t}$} & \multirow[t]{2}{*}{ Sig. } \\
\hline & $\mathrm{B}$ & Std. Error & Beta & & \\
\hline (Constant) & 157.539 & 21.923 & & 7.186 & $.000 * *$ \\
\hline Temperature & -2.410 & .607 & -.934 & -3.971 & $.000 * *$ \\
\hline Humidity & -.394 & .130 & -.713 & -3.033 & $.004 * *$ \\
\hline
\end{tabular}

The results that emerged from the regression model of temperature and humidity on respiratory rate reveal a divergent pattern from the models pertaining to systolic BP, diastolic BP and pulse rate. As shown in Table 5, the coefficients of determination (urban: $\mathrm{R}^{2} 0.06, \mathrm{~F}=1.19, \mathrm{P}>0.05$; mountain: $\mathrm{R}^{2} 0.11, \mathrm{~F}=2.38, \mathrm{P}>0.05$ ) indicate that the model is poor. This means that temperature and humidity account for very little variation $(6 \%$, $11 \%)$ in respiratory rate in both environments. Thus, it could be said that no significant relationship exists between temperature, humidity and respiratory rate $(\mathrm{P}>0.05)$ in the two environments.

Table 5. Multiple regression analysis of temperature and humidity on respiratory rate

\begin{tabular}{|c|c|c|c|c|c|}
\hline \multirow{2}{*}{$\begin{array}{l}\text { Model } \\
\text { (urban environment) }\end{array}$} & \multicolumn{2}{|c|}{ Unstandardized Coefficients } & \multirow{2}{*}{$\begin{array}{l}\text { Standardized Coefficients } \\
\text { Beta }\end{array}$} & \multirow[t]{2}{*}{$\mathrm{t}$} & \multirow[t]{2}{*}{ Sig. } \\
\hline & $\mathrm{B}$ & Std. Error & & & \\
\hline (Constant) & 18.631 & 6.067 & & 3.071 & .004 \\
\hline Temperature & .102 & .161 & -.135 & -.632 & $.531 *$ \\
\hline Humidity & -.022 & .034 & -.139 & -.647 & $.522 *$ \\
\hline \multicolumn{6}{|c|}{$\mathrm{F}=1.195, \mathrm{P}>0.05, \quad \mathrm{R}=.250^{\mathrm{b}}, \mathrm{R}^{2}=.062$} \\
\hline \multirow{2}{*}{$\begin{array}{l}\text { Model } \\
\text { (mountain environment) }\end{array}$} & \multicolumn{2}{|c|}{ Unstandardized Coefficients } & Standardized Coefficients & $\mathrm{t}$ & Sig. \\
\hline & $\mathrm{B}$ & Std. Error & Beta & & \\
\hline (Constant) & 29.475 & 7.888 & & 3.737 & .001 \\
\hline Temperature & -.350 & .218 & -.425 & -1.602 & $.118 *$ \\
\hline Humidity & -.019 & .047 & -.110 & -.415 & $.681 *$ \\
\hline
\end{tabular}

$\mathrm{F}=2.387, \mathrm{P}>0.05, \quad \mathrm{R}=.342^{\mathrm{b}}, \mathrm{R}^{2}=.117$

a. Dependent Variable: Respiratory rate, Significant at $0.05 \%$ (*Not Significant),

b. Independent Variables: Temperature, Humidity 


\section{Discussion}

On the whole, the findings of this study suggest that there is a statistically significant difference between the urban and the mountain landscape environment in terms of ambient conditions. They demonstrate that ambient environmental conditions influence the stress response mechanism of the individual. The foregoing builds on findings from Madsen and Nafstad (2006), who suggested that the effect of exposure to environmental conditions like temperature on the cardiovascular system is evident in blood pressure increases. Their study also revealed that a $10^{\circ} \mathrm{C}$ decrease in temperature is associated with an increase in blood pressure for both men and women. Specifically, the outcome of this study resembles that of Park et al. (2009), which revealed that diastolic $\mathrm{BP}$ and pulse rate decreased significantly after walking in the forest environment compared to the city, indicating enhanced relaxation.

These findings are also congruent with the work of Jansen et al. (2001), who revealed that ambient temperature has a moderate but significant influence on blood pressure. Additionally, they corroborate the study by Kunutsor and Powles (2010), which revealed a significant inverse relationship between ambient temperature and both systolic and diastolic BP. (Kunutsor and Powles (2010) found that systolic BP was lowered by $5 \mathrm{mmHg}$ per $10^{\circ} \mathrm{C}$ increase in temperature. This is also evident in the findings of the present study, which indicate that a unit increase in temperature and humidity accounts for a decrease in systolic BP and diastolic BP in the urban and mountain landscape environment respectively. These findings are, however, not in alignment with those of Charach et al. (2013), who suggested that variations in humidity are completely unrelated to blood pressure levels.

Similar to the findings pertaining to blood pressure, the inverse association of temperature and humidity with pulse rate implies that increases in temperature and humidity influence a reduction in pulse rate. While there have been several studies on the pulse rate response of individuals based on the comparison between urban and forest environments (Lee et al., 2012; Lee et al., 2014; Park, et al., 2009), none was found to consider the association between ambient conditions and pulse rate responses in a mountain environment. However, the significant relationship between ambient conditions and pulse rate indicates that blood pressure as well as pulse rate is considerably associated with temperature and humidity. Whereas systolic BP, diastolic BP and pulse rate showed significant relationships with temperature and humidity, respiratory rate did not show a significant relationship. The predictive strength of temperature and humidity on respiratory rate was weak, indicating that the relationship, though inverse, lacks much influence. In sum, this suggests that the relationship between ambient environment conditions and respiratory rate is not significant: thus, its influence on physiological response is minimal. Hence, the findings in this study suggest that a significant increase in temperature and relative humidity influenced reduced systolic BP, diastolic BP and pulse rate, whilst no change in respiratory rate was noted.

However, limitations based on variations in the physiological outcomes of individuals open more scope for further studies. One of these limitations stems from the measures of blood pressure, which was taken only once on each experimentation day due to cost constraints. It is known that blood pressure varies throughout the day depending on the psychological state of the individual, which greatly affects physiological outcomes. Another limitation of this study pertains to the continual fluctuations of ambient environment conditions, particularly temperature and humidity. Hence, ambulatory measurements of physiological indices should be utilized in further studies to check against variations influenced by fluctuations in blood pressure and ambient environment conditions.

\section{Conclusion}

Temperature and humidity are aspects of the mountain landscape environment that combine to influence human physiological wellbeing. Our findings indicate significant changes in blood pressure and pulse rate when individuals interact with varied ambient temperatures and humidity conditions. Further, comparison of these conditions between the urban and the mountain landscape environment revealed the significance of their effect on wellbeing. Therefore, essential empirical data is provided for use and implementation by landscape practitioners and policy makers in harnessing and managing mountain landscape environments. Hence, individuals confronted with many sources of stress from daily engagements in urban environments can obtain short term relief in the mountain landscape environment.

\section{References}

Abdulla, K., \& Taka, M. (1988). Climatic effects on blood pressure in normotensive and hypertensive subjects. Postgraduate Medical Journal, 64(747), 23-26. http://dx.doi.org/10.1136/pgmj.64.747.23

Bergdahl, J., \& Bergdahl, M. (2002). Perceived stress in adults: prevalence and association of depression, anxiety and medication in a Swedish population. Stress and Health, 18(5), 235-241. http://dx.doi.org/10. 1002/smi.946 
Berto, R. (2014). The role of nature in coping with psycho-physiological stress: a literature review on restorativeness. Behavioral Sciences, 4(4), 394-409. http://dx.doi.org/10.3390/bs4040394

Biaggioni, I. (2008). Circadian clocks, autonomic rhythms, and blood pressure dipping. Hypertension, 52(5), 797-798. http://dx.doi.org/10.1161/HYPERTENSIONAHA.108.117234

Brown, D. K., Barton, J. L., \& Gladwell, V. F. (2013). Viewing nature scenes positively affects recovery of autonomic function following acute-mental stress. Environmental science \& technology, 47(11), 5562-5569. http://dx.doi.org/10.1021/es305019p

Cairns Jr, J., McCormick, P. V., \& Niederlehner, B. (1993). A proposed framework for developing indicators of ecosystem health. Hydrobiologia, 263(1), 1-44. http://dx.doi.org/10.1007/BF00006084

Campbell, J., \& Ehlert, U. (2012). Acute psychosocial stress: does the emotional stress response correspond with physiological responses? Psychoneuroendocrinology, 37(8), 1111-1134. http://dx.doi.org/10.1016/j. psyneuen.2011.12.010

Charach, G., Shochat, M., Argov, O., Weintraub, M., Charach, L., Rabinovich, A., ... George, J. (2013). Seasonal changes in blood pressure: cardiac and cerebrovascular morbidity and mortality. World $J$ Hypertens, 3(1), 1-8. http://dx.doi.org/10.5494/wjh.v3.i1.1

Chen, Q., Wang, J., Tian, J., Tang, X., Yu, C., Marshall, R. J., ... Lv, J. (2013). Association between ambient temperature and blood pressure and blood pressure regulators: 1831 Hypertensive patients followed up for three years. PloS one, 8(12), e84522. http://dx.doi.org/10.1371/journal.pone.0084522

Chifamba, J., Mufunda, J., Sigola, L., Matenga, J., \& Sparks, H. (1998). Effect of variation in environmental temperature on blood pressure: is it important? The Central African journal of medicine, 44(2), 37-40.

Creswell, J. W. (2012). Educational research: Planning, conducting, and evaluating quantitative (4th ed.). Prentice Hall.

Hartig, T., Mitchell, R., De Vries, S., \& Frumkin, H. (2014). Nature and health. Annual Review of Public Health, 35, 207-228. http://dx.doi.org/10.1146/annurev-publhealth-032013-182443

Horiuchi, M., Endo, J., Takayama, N., Murase, K., Nishiyama, N., Saito, H., \& Fujiwara, A. (2014). Impact of Viewing vs. Not Viewing a Real Forest on Physiological and Psychological Responses in the Same Setting. International Journal of Environmental Research and Public Health, 11(10), 10883-10901. http://dx.doi.org/10.3390/ijerph111010883

Hozawa, A., Kuriyama, S., Shimazu, T., Ohmori-Matsuda, K., \& Tsuji, I. (2011). Seasonal variation in home blood pressure measurements and relation to outside temperature in Japan. Clinical and experimental hypertension, 33(3), 153-158. http://dx.doi.org/10.3109/10641963.2010.531841

Hughes, A. M., Volante, W. G., Stowers, K., Leyva, K., Oglesby, J. M., Bisbey, T., ... Vidulich, M. A. (2014). Cognition and Physiological Response Towards a Model of Validated Physiological Measurement. Proceedings of the 2014 Proceedings of the Human Factors and Ergonomics Society Annual Meeting: Sage Publications, 1009-1013. http://dx.doi.org/10.1177/1541931214581211

Jamaludin, A. A., Hussein, H., Daud, N. K., Ariffin, M., \& Rosemary, A. (2013). Living behaviour assessment at residential college building with bioclimatic design strategies.

Jansen, P., Leineweber, M., \& Thien, T. (2001). The effect of a change in ambient temperature on blood pressure in normotensives. Journal of human hypertension, 15(2), 113-117. http://dx.doi.org/10.1038/sj.jhh.1001134

Kajantie, E., \& Phillips, D. I. (2006). The effects of sex and hormonal status on the physiological response to acute psychosocial stress. Psychoneuroendocrinology, 31(2), 151-178. http://dx.doi.org/10.1016/j.psyneuen. 2005.07.002

Kampmann, B., \& Bröde, P. (2009). Physiological Responses to Temperature and Humidity compared with Predictions of PHS and WBGT. Environmental Ergonomics XIII, University of Wollongong, Wollongong, 54-58.

Kaplan, R. (2001). The nature of the view from home psychological benefits. Environment and behavior, 33(4), 507-542. http://dx.doi.org/10.1177/00139160121973115

Kaplan, R., \& Kaplan, S. (2011). Well-being, Reasonableness, and the Natural Environment. Applied Psychology: Health and Well-Being, 3(3), 304-321. http://dx.doi.org/10.1111/j.1758-0854.2011.01055.x 
Kunutsor, S. K., \& Powles, J. W. (2010). The effect of ambient temperature on blood pressure in a rural West African adult population: a cross-sectional study: cardiovascular topics. Cardiovascular journal of Africa, 21(1), 17-20.

Lee, H.-Y., \& Oh, B.-H. (2010). Aging and arterial stiffness. Circulation Journal, 74(11), 2257-2262. http://dx.doi.org/10.1253/circj.CJ-10-0910

Lee, J., Park, B.-J., Tsunetsugu, Y., Kagawa, T., \& Miyazaki, Y. (2009). Restorative effects of viewing real forest landscapes, based on a comparison with urban landscapes. Scandinavian Journal of Forest Research, 24(3), 227-234. http://dx.doi.org/10.1080/02827580902903341

Lee, J., Park, B.-J., Tyrväinen, L., Li, Q., Kagawa, T., Miyazaki, Y., \& Tsunetsugu, Y. (2012). Nature therapy and preventive medicine. INTECH Open Access Publisher. http://dx.doi.org/10.5772/37701

Lee, J., Tsunetsugu, Y., Takayama, N., Park, B.-J., Li, Q., Song, C., ... Kagawa, T. (2014). Influence of forest therapy on cardiovascular relaxation in young adults. Evidence-Based Complementary and Alternative Medicine, 2014. http://dx.doi.org/10.1155/2014/834360

Lee, M.-S., Park, B.-J., Lee, J., Park, K.-T., Ku, J.-H., Lee, J.-W., ... Miyazaki, Y. (2013). Physiological relaxation induced by horticultural activity: transplanting work using flowering plants. Journal of Physiological Anthropology, 32(1), 15. http://dx.doi.org/10.1186/1880-6805-32-15

Lin, N., \& Lai, G. (1995). Urban stress in China. Social Science \& Medicine, 41(8), 1131-1145. http://dx.doi.org/ 10.1016/0277-9536(94)00426-T

Madsen, C., \& Nafstad, P. (2006). Associations between environmental exposure and blood pressure among participants in the Oslo Health Study (HUBRO). European Journal of Epidemiology, 21(7), 485-491. http://dx.doi.org/10.1007/s10654-006-9025-x

Modesti, P. A., Morabito, M., Bertolozzi, I., Massetti, L., Panci, G., Lumachi, C., ... Lonati, L. (2006). Weather-related changes in 24-hour blood pressure profile effects of age and implications for hypertension management. Hypertension, 47(2), 155-161. http://dx.doi.org/10.1161/01.HYP.0000199192.17126.d4

Murakami, S., Otsuka, K., Kono, T., Soyama, A., Umeda, T., Yamamoto, N., ... Kitaura, Y. (2011). Impact of outdoor temperature on prewaking morning surge and nocturnal decline in blood pressure in a Japanese population. Hypertension Research, 34(1), 70-73. http://dx.doi.org/10.1038/hr.2010.176

Nater, U. M., Rohleder, N., Gaab, J., Berger, S., Jud, A., Kirschbaum, C., \& Ehlert, U. (2005). Human salivary alpha-amylase reactivity in a psychosocial stress paradigm. International Journal of Psychophysiology, 55(3), 333-342. http://dx.doi.org/10.1016/j.ijpsycho.2004.09.009

O'Brien, E., Asmar, R., Beilin, L., Imai, Y., Mallion, J.-M., Mancia, G., .. Palatini, P. (2003). European Society of Hypertension recommendations for conventional, ambulatory and home blood pressure measurement. Journal of Hypertension, 21(5), 821-848. http://dx.doi.org/10.1097/00004872-200305000-00001

Ochiai, H., Ikei, H., Song, C., Kobayashi, M., Takamatsu, A., Miura, T., ... Imai, M. (2015). Physiological and Psychological Effects of Forest Therapy on Middle-Aged Males with High-Normal Blood Pressure. International Journal of Environmental Research and Public Health, 12(3), 2532-2542. http://dx.doi.org/10. 3390/ijerph120302532

Okada, M., \& Kakehashi, M. (2014). Effects of outdoor temperature on changes in physiological variables before and after lunch in healthy women. International Journal of Biometeorology, 58(9), 1973-1981. http://dx.doi.org/10.1007/s00484-014-0800-1

Pan, R.-C., Chen, B., \& Li, J.-J. (1993). Noninvasive monitoring of autonomic cardiovascular control during stress. Proceedings of the 1993 Bioengineering Conference, 1993., Proceedings of the 1993 IEEE Nineteenth Annual Northeast: IEEE, 187-188. http://dx.doi.org/10.1109/nebc.1993.404361

Park, B.-J., Tsunetsugu, Y., Kasetani, T., Hirano, H., Kagawa, T., Sato, M., \& Miyazaki, Y. (2007). Physiological effects of Shinrin-yoku (taking in the atmosphere of the forest)-using salivary cortisol and cerebral activity as indicators. Journal of Physiological Anthropology, 26(2), 123-128. http://dx.doi.org/10. 2114/jpa2.26.123

Park, B.-J., Tsunetsugu, Y., Kasetani, T., Morikawa, T., Kagawa, T., \& Miyazaki, Y. (2009). Physiological effects of forest recreation in a young conifer forest in Hinokage town, Japan. Silva Fennica, 43(2), 291-301. http://dx.doi.org/10.14214/sf.213 
Probst, T. M. (2013). Conducting Effective Stress Intervention Research: Strategies for Achieving an Elusive Goal. Stress and Health, 29(1), 1-4. http://dx.doi.org/10.1002/smi.2482

Tsunetsugu, Y., Lee, J., Park, B.-J., Tyrväinen, L., Kagawa, T., \& Miyazaki, Y. (2013). Physiological and psychological effects of viewing urban forest landscapes assessed by multiple measurements. Landscape and Urban Planning, 113, 90-93. http://dx.doi.org/10.1016/j.landurbplan.2013.01.014

Ulrich, R. S., Simons, R. F., Losito, B. D., Fiorito, E., Miles, M. A., \& Zelson, M. (1991). Stress recovery during exposure to natural and urban environments. Journal of environmental psychology, 11(3), 201-230. http://dx.doi.org/10.1016/S0272-4944(05)80184-7

van den Berg, A. E., Maas, J., Verheij, R. A., \& Groenewegen, P. P. (2010). Green space as a buffer between stressful life events and health. Social Science \& Medicine, 70(8), 1203-1210. http://dx.doi.org/10.1016/ j.socscimed.2010.01.002

Waghmare, M., \& Chatur, P. (2012). Temperature and Humidity Analysis using Data Logger of Data Acquisition System: An Approach. International Journal of Emerging Technology and Advanced Engineering, 2(1), 102-106.

Waterhouse, J., Reilly, T., \& Edwards, B. (2004). The stress of travel. Journal of Sports Sciences, 22(10), 946-966. http://dx.doi.org/10.1080/02640410400000264

Weathington, B. L., Cunningham, C. J., \& Pittenger, D. J. (2010). Research Methods for the Behavioral and Social Sciences. John Wiley \& Sons.

Yamaguchi, M., Deguchi, M., \& Miyazaki, Y. (2006). The effects of exercise in forest and urban environments on sympathetic nervous activity of normal young adults. Journal of International Medical Research, 34(2), 152-159. http://dx.doi.org/10.1177/147323000603400204

Yang, T., Rockett, I. R., Lv, Q., \& Cottrell, R. R. (2012). Stress status and related characteristics among urban residents: a six-province capital cities study in China. PloS One, 7(1), e30521. http://dx.doi.org/ 10.1371/journal.pone.0030521

\section{Copyrights}

Copyright for this article is retained by the author(s), with first publication rights granted to the journal.

This is an open-access article distributed under the terms and conditions of the Creative Commons Attribution license (http://creativecommons.org/licenses/by/4.0/). 